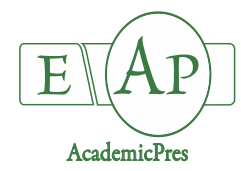

Orhan E et al. (2020)

Notulae Botanicae Horti Agrobotanici Cluj-Napoca 48(2):579-557

DOI: $10.15835 /$ nbha48211928

Research Article

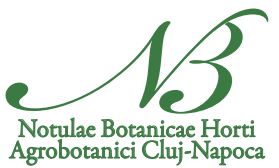

\title{
Molecular characterization of mulberry genotypes and species in Turkey
}

\section{Emine ORHAN ${ }^{1}$, Meleksen AKIN ${ }^{2}$, Sadiye P. EYDURAN ${ }^{2}$, Sezai ERCISLI ${ }^{3 *}$}

\footnotetext{
${ }^{1}$ Ataturk University, Agricultural Faculty, Department of Agricultural Biotechnology, Erzurum, Turkey; eorhan11@gmail.com ${ }^{2}$ Igdir University, Agricultural Faculty, Department of Horticulture, Igdir, Turkey; akinmeleksen@gmail.com; peralatilla@gmail.com ${ }^{3}$ Ataturk University, Agricultural Faculty, Department of Horticulture,Erzurum, Turkey; sercisli@gmail.com (*corresponding author)
}

\begin{abstract}
Mulberries are one of the most important traditional fruit in Turkey and either consumed fresh or processed into several traditional products. Mulberry trees (genotypes) belong to Morus alba L., Morus nigra L., and Morus rubra L. shows high phenotypic diversity. In this study, 26 genotypes of Morus nigra, 21 genotypes of Morus rubra and 26 genotypes and landraces of Morus alba sampled from different parts of eastern Anatolia region in Turkey were fingerprinted using 16 simple sequence repeat (SSR) markers. Among SSR markers, the number of alleles per locus ranged from 2 (SS01, SS05) to 11 (MulSTR3) with an average of 5.19. A total of 83 alleles were obtained for the 16 SSR markers. The polymorphic information content ranged from 0.43 to 0.84 with an average of 0.61 per locus. In this study, MulSTR3, MulSTR5, MulSTR6, SS04 and SS20 were found to be the most useful SSR markers to detect genetic differences between mulberry species, genotypes and landraces. Genetic similarity ratio ranged from 0.24 to 0.94 with a mean similarity value of 0.41 indicating a high level of polymorphism among the mulberry species, genotypes and landraces. Clustering based on Jaccard's similarity coefficient and an unweighted pair group method with arithmetic mean (UPGMA) revealed 3 main clusters that corresponded with species. The results of the present study indicate that white mulberry landraces and genotypes were more diverse than the red and black mulberry genotypes. Therefore, white mulberry genotypes can be a good source for the mulberry-breeding programme due to its better genetic diversity as well as its high economical and yield properties.
\end{abstract}

Keywords: landraces; molecular characterization; mulberry species; seed propagation; SSR

\section{Introduction}

The fruiting mulberry placed in the Morus genus, Moraceae family. The widely distributed and used mulberries in the world come from the three main species: white mulberry (Morus alba), red mulberry (Morus rubra), and the black mulberry (Morus nigra) (Gungor and Sengul, 2008). The three major mulberry species originated from different areas of the world. The red mulberry (the American mulberry) is native to eastern 
United States. The white mulberry, bred for silkworm production and fruit cultivation, is native to China. The black mulberry is native to Asia (Ercisli and Orhan, 2007; Kafkas et al., 2008; Vijayan et al., 2008).

Mulberries can be found in many parts of the world; yet they originated in the Far East along the Silk Road from China to Turkey. As the silkworm's food of choice, mulberry trees flanked the famous route that traded goods and culture between China, Persia, Europe, the Horn of Africa and the Arabian Peninsula. Mulberry trees belong to different Morus species today spread throughout all regions from the tropics to the sub-arctic and from sea level to altitudes as high as $4000 \mathrm{~m}$ (Darias-Martin et al., 2003; Arabshahi-Delouee and Urooj, 2007; Ercisli and Orhan, 2007).

Mulberry fruits contain considerable amounts of biologically active ingredients that might be associated with some potential pharmacological activities. Thus, they are beneficial for health and are categorized as super foods. In most mulberry-growing countries, mulberry fruit is commonly eaten fresh, dried, or processed into wine, fruit juice, and jam for its delicious taste, pleasing colour, low calorie content, and high nutrient content (Gungor and Sengul, 2008; Yuan and Zhao, 2017; Zhang et al., 2018).

Genetic variations are the raw materials of plant breeding and have been increasingly narrowed due to various reasons. Landraces and unnamed genotypes are repository of gene pool that enrich biodiversity and maintain and stabilize ecosystem in a sustainable way to make it functional. They are also genetically diverse and locally adapted and associated with a set of farmers' practices of seed selection and field management as well as with a farmers' knowledge base (Camacho-Villa et al., 2005). Determination of the level of variation within the landraces and unnamed genotypes is very important for their preservation. For landraces and unnamed genotypes to be employed in plant breeding programs their levels of genetic variation should first be determined (Dwivedi et al., 2016).

Continuous seed propagation for thousands of years in Turkey has given rise to a great number of seedling mulberry trees, which represent valuable mulberry genetic resources. Although many valuable mulberry trees were cut for their precious timber, there are still important mulberry populations of great genetic variation having resistance to pests and diseases, yield and fruit quality in Anatolia which has led to many researches of selection (Aslan, 1998; Ercisli and Orhan, 2008; Orhan, 2009).

Mulberry genotypes vary greatly in phenotypically (Thangavelu et al., 1997; Cam and Turkoglu, 2004; Orhan et al., 2007), and tools for distinguishing among them are lacking. Therefore, a method to easily and accurately identify mulberry genotypes is greatly needed; such a method would also benefit breeders and planters. Mulberry genotypes are usually distinguished based on morphology (Aslan, 1998; Cam and Turkoglu, 2004; Orhan, 2009). However, morphological studies are preliminary breeding approaches, and morphological traits are usually quantitative, meaning that they are easily controlled by the environment and thus exhibit high variability (Andersen and Lubberstedt, 2003). In addition, similar characters cannot be distinguished by morphology (Orhan, 2009). To overcome these problems, molecular methods such as randomly amplified polymorphic DNA (RAPD) (Orhan et al., 2007), inter-simple sequence repeat (ISSR) (Vijayan et al., 2005) and amplified fragment-length polymorphism (AFLP) (Kafkas et al., 2008) has been used in mulberry classification. All above methods approved insufficient for the identification of mulberry genotypes; thus, there is a great need to establish an accurate and easy way to distinguish mulberry genotypes, landraces, cultivars and to determine relationships between species as well. Among available molecular markers, microsatellite markers or SSR (Simple Sequence Repeat) are widely used in genetic analyses of plants including mulberry, since they show considerable advantages such as co-dominance, multiallelism, high frequency and random distribution in the genome, and high level of polymorphism (Ercisli et al., 2011; Guney et al., 2018; Garcia-Gomez et al., 2019). SSR markers are characterized by sequences, also called motifs, from one to six nucleotides, which are repeated in tandem, considering that the polymorphism produced consists of the difference in the number of replicates of motifs in each allele (Eyduran et al. 2016).

To our knowledge, a detailed compilation of research regarding the SSR based molecular characterization of mulberry species, genotypes and landraces is lacking. Knowledge of genetic diversity and 
relationships among the mulberry germplasm will play a significant role in local and regional breeding programmes. Therefore, the objective of the present study was to determine the genetic relationship among 73 mulberry genotypes/landraces using SSR markers to identify genetically divergent genotypes for breeding.

\section{Materials and Methods}

\section{Plant material}

In total 73 mulberry genotypes (26 genotypes of Morus nigra, 21 genotypes of Morus rubra and 26 genotypes of Morus alba) sampled from Eastern Anatolia region in Turkey in 2016 were used in SSR analysis.

\section{DNA extraction}

Genomic DNA was extracted from young leaf tissues using the Wizard ${ }^{\circ}$ Genomic DNA Purification Kit (Promega, Madison, WI) according to the instructions provided by the manufacturer. Subsequently, an RNase treatment was performed the eluted DNA samples. Purity and concentration of the DNA were checked both on $1 \%(\mathrm{w} / \mathrm{v})$ agarose gels and by NanoDrop ${ }^{\circ}$ ND-1000 Spectrophotometer.

\section{SSR analysis}

Sixteen nuclear SSR markers of primers flanking SSR sequences previously characterized and developed for Morus were used. These are MulSTR1, MulSTR2, MulSTR3, MulSTR4, MUISTR5, MulSTR6 (Aggarwal et al., 2004) and SS01, SS02, SS04, SS05, SS06, SS09, SS17, SS18, SS19 and SS20 (Zhao et al., 2005) (Table 1).

\section{Polymerase Chain Reaction}

PCR was conducted in a volume of $10 \mu \mathrm{L}$ and contained 15 ng genomic DNA, 5 pmol of each primer, $0.5 \mathrm{mM}$ dNTP, 0.5 unit GoTaq DNA polymerase (Promega), $1.5 \mathrm{mM} \mathrm{MgCl}_{2}$ and $2 \mu \mathrm{L} 5 \mathrm{X}$ buffer. The forward primers were "labelled" with WellRED fluorescent dyes D2 (black), D3 (green) and D4 (blue) (Proligo, Paris, France). Reactions without DNA were included as negative controls. PCR amplification was performed using the Biometra ${ }^{\circ}$ PCR System. The amplification conditions consisted of an initial denaturation step of $3 \mathrm{~min}$ at $94^{\circ} \mathrm{C}$, followed by 35 cycles of $1 \mathrm{~min}$ at $94^{\circ} \mathrm{C}, 1 \mathrm{~min}$ at $52-56^{\circ} \mathrm{C}$ and 2 mins at $72^{\circ} \mathrm{C}$ with a final extension at $72^{\circ} \mathrm{C}$ for 10 mins. Determination of polymorphisms, the PCR products were run on CEQTM $8800 \mathrm{XL}$ Capillary Genetic Analysis System (Beckman Coulter, Fullerton, CA). The analyses were repeated at least twice to ensure reproducibility of the results.

\section{Data analysis and genetic relationships}

The genetic analysis program "IDENTITY" 1.0 (Wagner and Sefc, 1999) was used according to Paetkau et al. (1995) for the calculation of number of alleles, expected and observed heterozygosity. Genetic similarity was determined by the program "MICROSAT" (version 1.5) (Minch et al., 1995) using proportion of shared alleles, which was calculated by using "ps (option 1 - (ps))", as described by Bowcock et al. (1994). The results were then converted to a similarity matrix, and a dendrogram was constructed with the UPGMA method (Sneath and Sokal 1973) using the software NTSYS-pc (Numerical Taxonomy and Multiware Analysis System, version 2.0) (Rohlf 1988). Polymorphic Information Content (PIC) was calculated according to Kalinowski et al. (2007). The principal coordinate analysis (PCoA) was performed to show the relationships and differentiation of the mulberry genotypes in a three-dimensional array of eigenvectors, using the DCENTER and EIGEN modules of NTSYS-pc 2.10e software. 


\section{Results and Discussion}

In this study sixteen published primer pairs flanking nuclear microsatellites were employed to investigate the level of genetic variation among the 73 mulberry genotypes that belongs to Morus nigra, Morus rubra and Morus alba sampled different parts of eastern Anatolia in Turkey.

In total, 83 alleles were obtained at the 16 SSRs loci analysed. Results showed that the number of alleles per locus ranged from 2 (SS01 and SS05) to 11 (MulSTR3) with a mean number of 5.19 alleles per locus (Table 1). The highest number of alleles was observed at loci MulSTR3 as 11 and followed by MulSTR5 and MulSTR6 as 8 alleles, respectively (Table 1). In literature a few reports are available on SSR analysis of mulberry genotypes. Garcia-Gomez et al. (2019) used thirty-seven mulberry genotypes from nine different countries including Cuba, Costa Rica, Brazil, South Korea, China, Japan, Italy, Ethiopia and Spain. In SSR analysis, they obtained the number of alleles from 2 (SS19) to 19 (MulSTR3), with a total of 68 alleles for the 9 loci and an average of 7.55 bands per locus. Wangari et al. (2013) used ten mulberry accessions, which included five Morus alba and five Morus indica genotypes in SSR analysis. They used 15 SSR primers and obtained a total of 35 alleles with an average of 6.3 per locus. They obtained the highest number of alleles from SS09 primer as 15, while the lowest number of alleles generated by SS19, SS20, MulSTR2, MulSTR6 and MulSTR5 primers as 2. Aggarwal et al. (2004) reported mean number of alleles as 18.6 in mulberries while Zhao et al. (2007) reported average 5.13 alleles per locus by using SSR markers in mulberry genotypes. Wani et al. (2013) characterized 17 mulberry genotypes by 6 SSR markers. The molecular analysis of those genotypes showed significant variability. They obtained a total of 17 alleles across the 17 mulberry genotypes using 6 SSR markers. They determined the number of alleles per loci generated by these SSR markers varied from 2 (MulSTR3) to 4 (MulSTR4) with an average of 2.84 per locus indicating lower values than our study. The existence of the variability in the number of alleles reported by other studies could be due to difference in selected genotypes and primers.

Table 1. Number of detected alleles, observed heterozygosity $(\mathrm{Ho})$, expected heterozygosity $(\mathrm{He})$ and polymorphism information content (PIC) of 16 SSR markers on 73 genotypes of mulberry species

\begin{tabular}{|c|c|c|c|c|}
\hline $\begin{array}{c}\text { SSR } \\
\text { Primers }\end{array}$ & $\begin{array}{c}\text { Number of } \\
\text { alleles }\end{array}$ & $\begin{array}{c}\text { Observed } \\
\text { heterozygosity } \\
(\mathrm{Ho})\end{array}$ & $\begin{array}{c}\text { Expected } \\
\text { heterozygosity } \\
(\mathrm{He})\end{array}$ & PIC \\
\hline MulSTR1 & 6 & 0.65 & 0.52 & 0.56 \\
\hline MulSTR2 & 6 & 0.56 & 0.49 & 0.67 \\
\hline MulSTR3 & 11 & 0.71 & 0.50 & 0.84 \\
\hline MulSTR4 & 4 & 0.55 & 0.71 & 0.56 \\
\hline MulSTR5 & 8 & 0.69 & 0.60 & 0.72 \\
\hline MulSTR6 & 8 & 0.77 & 0.50 & 0.45 \\
\hline SS01 & 2 & 0.50 & 0.60 & 0.66 \\
\hline SS02 & 5 & 0.55 & 0.39 & 0.55 \\
\hline SS04 & 7 & 0.64 & 0.44 & 0.52 \\
\hline SS05 & 2 & 0.53 & 0.55 & 0.56 \\
\hline SS06 & 3 & 0.57 & 0.51 & 0.60 \\
\hline SS09 & 3 & 0.60 & 0.50 & 0.54 \\
\hline SS17 & 5 & 0.70 & 0.45 & 0.43 \\
\hline SS18 & 3 & 0.62 & 0.60 & 0.64 \\
\hline SS19 & 3 & 0.55 & 0.52 & 0.61 \\
\hline SS20 & 7 & 0.64 & & \\
\hline Average & 5.19 & 0.61 & & \\
\hline
\end{tabular}


The observed and expected heterozygosity were found between 0.53 (SS05) and 0.77 (MulSTR6), 0.39 (SS05) and 0.71 (MulSTR5), respectively (Table 1). The average observed and expected heterozygosity were found as 0.61 and 0.52 , respectively. Results clearly indicating that our outcrossing mulberry genotypes have shown high degree of heterozygosity. Garcia-Gomez et al. (2019) used thirty-seven mulberry genotypes from nine different countries in the SSR analysis and they observed of SSR markers heterozygosity ranged from 0.0 (SS19) to 0.91 (MulSTR3), with a mean of 0.52. Wangari et al. (2013) used ten mulberry accessions, which included five Morus alba and five Morus indica genotypes in SSR analysis. They used 15 SSR primers and obtained mean observed $(\mathrm{Ho})$ and expected $(\mathrm{He})$ heterozygosity as 0.37 and 0.36 , respectively. Zhao et al. (2005) reported Ho and $\mathrm{He}$ as 0.43 and 0.51 in 27 mulberry genotypes. Aggarwal et al. (2004) also reported a higher Ho value of 0.59 across 45 mulberry genotypes from species of diverse origin using SSR markers. Our results are in general comparable even indicating higher observed and expected heterozygosity than above studies and our findings reveals a high genetic variability among the mulberry genotypes. This implies, there is a high genetic variability among mulberry genotypes grown in Turkey.

Polymorphic information content (PIC) is a widely used measure of the usefulness of a molecular marker and therefore the PIC values were calculated for all primers (Table 1). The average PIC value was obtained as 0.61 . The most informative loci were MulSTR3 (0.84), while the least informative loci were SS19 (0.43), respectively. According to our results ten loci as informative markers (PIC $>0.5$ ) and four loci as suitable for mapping (PIC>0.7) (Table 1). These results indicate that all the markers could contribute substantial information to mulberry genetics and breeding research. The results also show that the mulberry populations of eastern Anatolia have relatively high levels of genetic diversity. Wani et al. (2013) characterized 17 mulberry genotypes by 6 SSR markers and they obtained PIC values between 0.26 (MulSTR3) and 0.62 (MulSTR4), with an average of 0.44 per locus indicating lower values than our study. However same 6 SSR markers utilized by Ramesh et al. (2004) produced a polymorphic information content from 0.85 to 0.90 among the 43 mulberry genotypes indicating higher values than our study. Zhao et al. (2007) used twenty-seven mulberry genotypes representing 11 species and three varieties of genus Morus and found PIC values from 0.20 to 0.68, with an average of 0.45 . The main propagation system of mulberries through seed should be the responsible of this great diversity (Orhan, 2009).

The dendrogram, in general, separated 73 genotypes into 3 main clusters, which indicates the heterogeneity of the seed propagated mulberry genotypes/landraces in the eastern Anatolia region in Turkey (Figure 1). Cluster I represent 26 Morus nigra genotypes and clearly separated from the other species and further divided 2 subgroups. Morus nigra genotypes showed close genetic relationships and lower genetic diversity. The similarity ratio among Morus nigra genotypes was between S7 and S11 (0.95) and S2 and S9 (0.69), with an average of 0.77 (Figure 1). Cluster II consisted of 21 Morus rubra genotypes and could be further divided 2 sub-clusters. The genetic diversity among Morus rubra genotypes higher than Morus nigra (Figure 1). In cluster II the closest Morus rubra genotypes were K2 and K5 with 0.88 while the most distant genotypes were $\mathrm{K} 4$ and $\mathrm{K} 7$ with 0.55 similarity ratio. The average similarity ratio among Morus rubra genotypes was 0.62 . Cluster III consisted of 26 Morus alba genotypes and local cultivars (landraces). In cluster III local cultivars and genotypes formed mixed population and cluster III further divided 2 sub-cluster. Cluster III is the most diverse group compared cluster I and II (Figure 1). In another word among 3 Morus species the genetic diversity was the highest among Morus alba followed by Morus rubra and Morus nigra. The closest genotypes/landraces in cluster III were Angut 3 and Angut 4 with 0.80 similarity ratio whereas the most distant genotypes in cluster III were Kastamonu and Kemaliye 3 with 0.42 similarity ratio. The average similarity ratio among 26 Morus alba genotypes/landraces was 0.46 . Such a wide interval of similarity values indicates a wide range of genetic diversity in the mulberry genotypes analysed in this study. Furthermore, the genotypes originating from the seedlings also affect the present results. In Turkey most of the mulberry trees non-grafted, which increases the genetic variation in mulberry germplasm, and offers an opportunity for breeders to select the best genotypes. 
Genotypes collected from various parts of eastern Anatolia showed diverse clustering; this may be due to outcrossing nature of mulberry.

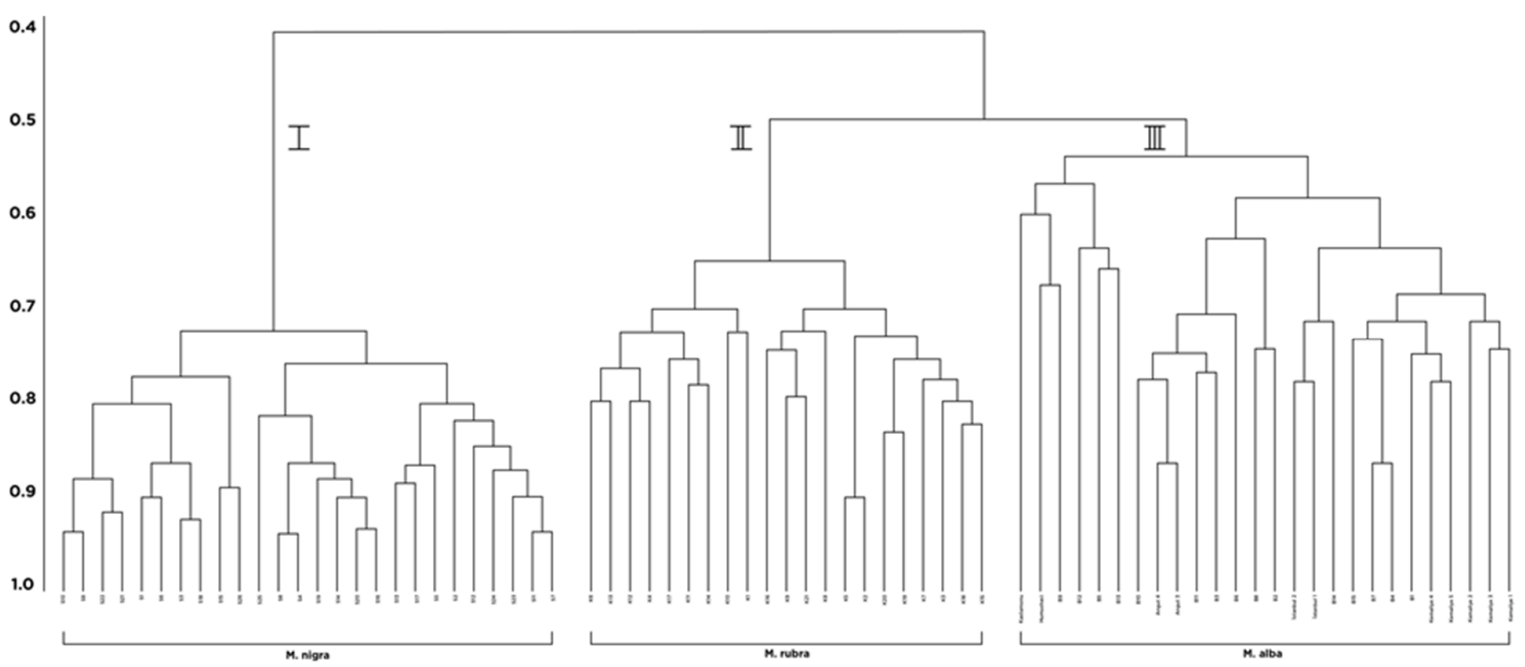

Figure 1. The UPGMA dendrogram based on simple matching similarity matrix obtained using 16 SSR markers, illustrating the relative similarity among 73 genotypes, of different Morus species

Principal coordinate analysis ( $\mathrm{PCoA})$ indicates that the three first 3 principal coordinates explain 45.1, 24.4 , and $9.5 \%$, respectively, accounting for $79.0 \%$ of the genetic similarity variance (Figure 2 ).

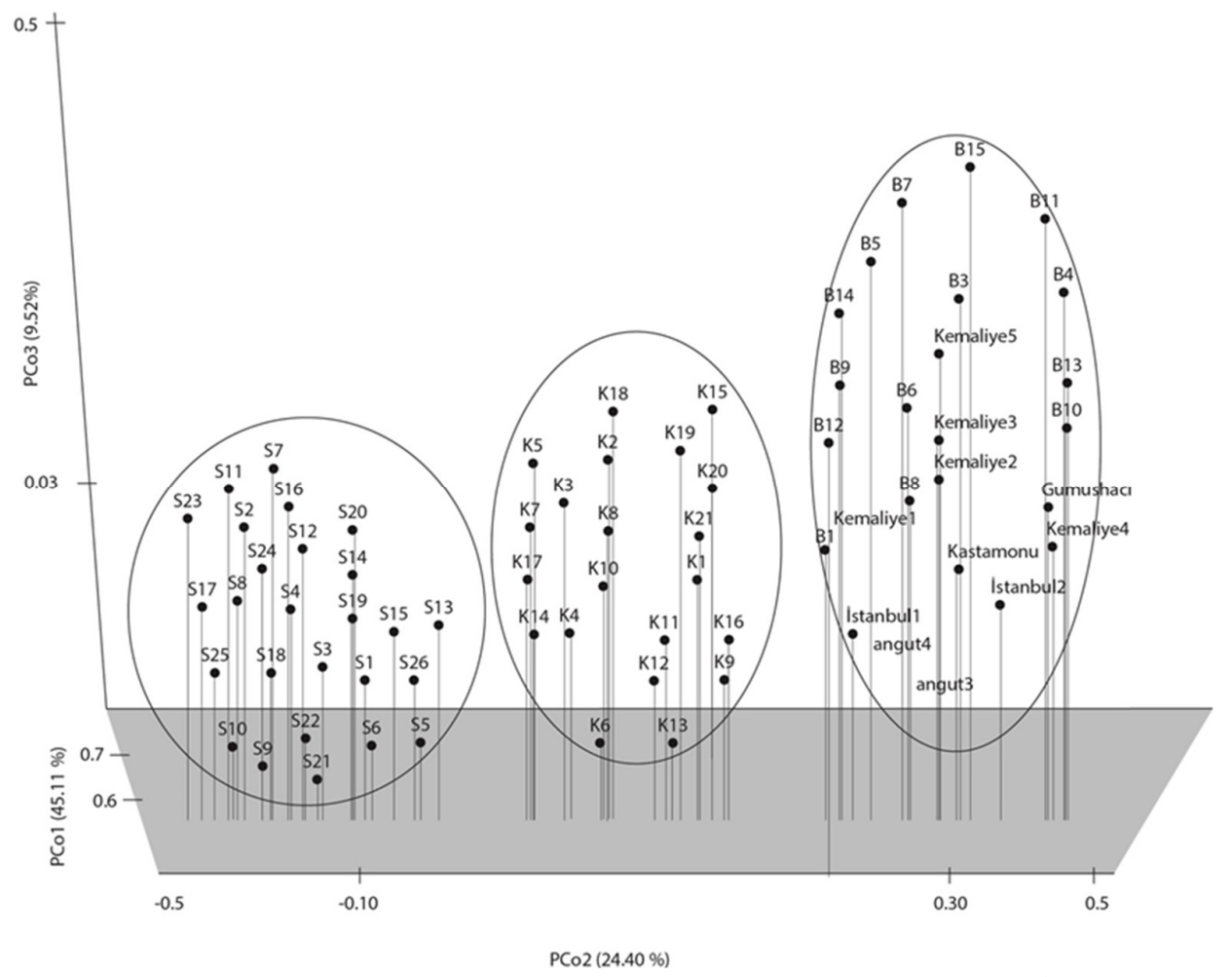

Figure 2. PCoA plot for the Morus nigra L, Morus rubra L. and Morus alba L. genotypes (S: Morus nigra; K: Morus rubra; B: Morus alba) 
These mulberry genotypes samples were partitioned into 3 distinct groups. PCoA Group 1 included only Morus nigra samples. PCoA Group 2 included Morus rubra samples and PCoA Group 3 included only Morus alba samples and genetic diversity was lowest among Morus nigra genotypes and was the highest among Morus alba genotypes (Figure 2) and in general consistent with the results of cluster analysis. The group 1 characterized by early ripening time. The genetic diversity higher in Group 2 than in Group 1. The markers employed here should be useful for the characterization and comparison of mulberry germplasm collections and for the detection of propagation errors. The evaluation of the molecular diversity of mulberry genetic resources is important for the optimal development of programs aimed at conservation. These markers were able to identify uniquely all the mulberry species and genotypes studied.

\section{Conclusions}

In conclusion, the current study found the existence of reasonable variability among the tested 73 Morus nigra, Morus rubra and Morus alba genotypes/landraces, which could be exploited for future breeding. The results revealed that 16 selected SSR markers were highly polymorphic and sufficiently distinguished the tested mulberry species, genotypes/landraces. The cluster analysis classified the 73 mulberry genotypes into three major distinct genetic groups respective of the source of species. Hence, the information generated will contribute significantly to mulberry improvement in Turkey.

\section{Acknowledgements}

This research received no specific grant from any funding agency in the public, commercial, or not-forprofit sectors.

\section{Conflict of Interests}

The authors declare that there are no conflicts of interest related to this article.

\section{References}

Andersen JR, Lubberstedt T (2003). Functional markers in plants. Trends in Plant Science 8(11):554-560.

Aggarwal RK, Udayakumar D, Hendre PS, Sarkar A, Singh LI (2004). Isolation and Characterization of six novel microsatelite markers for mulberry (Morus indica). Molecular Ecology 4:477-479.

Arabshahi-Delouee S, Urooj A (2007). Antioxidant properties of various solvent extracts of mulberry (Morus indica L.) leaves. Food Chemistry 102(4):1233-1240.

Aslan, MM (1998). Selection of promising mulberry type in Malatya, Elazı̆̆, Erzincan and Tunceli. Çukurova University. Institute of Science and Technology, Department of Horticulture, M.Sc. Adana pp 67.

Bowcock AM, Ruiz-Linares A, Tomfohrde J, Minch E, Kidd JR, Cavalli-Sforza LL (1994). High resolution of human evolutionary trees with polymorphic microsatellites. Nature 368:455-457.

Cam I, Turkoglu N (2004). Studies on some phenological and pomological traits of mulberries grown in Edremit and Gevaş region. Journal of Agricultural Science 14(2):127-131.

Camacho-Villa TC, Maxted N, Scholten M, Ford-Lloyd B (2005). Defining and identifying crop landraces. Plant Genet Resources: Characterisation and Utilisation 3:373-384.

Darias-Martin J, Lobo-Rodrigo G, Hernandez-Cordero J, Diaz-Diaz E, Diaz-Romero C (2003). Alcoholic beverages obtained from black mulberry. Food Technology and Biotechnology 41(2):173-176. 
Dwivedi SL, Ceccarelli S, Blair MW, Upadhyaya HD, Are AK, Ortiz R (2016). Landrace germplasm for improving yield and abiotic stress adaptation. Trends in Plant Science 21(1):31-42.

Ercisli S, Orhan E (2007). Chemical composition of white (Morus alba), red (Morus rubra) and black (M. nigra) mulberry fruits. Food Chemistry 103(4):1380-1384.

Ercisli S, Orhan E (2008). Some physico-chemical characteristics of black mulberry (Morus nigra L.) genotypes from Northeast Anatolia Region of Turkey. Scientia Horticulturae 116:41-46.

Ercisli S, Ipek A, Barut E (2011). SSR marker-based DNA fingerprinting and cultivar identification of olives (Olea europaea). Biochemical Genetics 49(9-10):555-561.

Eyduran SP, Ercisli S, Akin M, Eyduran E (2016). Genetic characterization of autochthonous grapevine cultivars from Eastern Turkey by simple sequence repeats (SSRs). Biotechnology and Biotechnological Equipment 30:26-31.

Garcia-Gomez B, Gonzalez-Alvarez H, Martinez-Mora C, Cenis JL, Perez-Hernandez MDC, Martinez-Zubiaur Y, Martinez-Gomez P (2019). The molecular characterization of an extended mulberry germplasm by SSR markers. Genetika 51(2):389-403.

Guney M, Kafkas S, Keles H, Aras S, Ercisli S (2018). Characterization of hawthorn (Crataegus spp.) genotypes by SSR markers. Physiology and Molecular Biology of Plants 24(6):1221-1230.

Gungor N, Sengul M (2008). Antioxidant activity, total phenolic content and selected physicochemical properties of white mulberry (Morus alba L.) fruits. International Journal of Food Properties 11:44-52.

Kafkas S, Ozgen M, Dogan Y, Ozcan B, Ercisli S, Serce S (2008). Molecular characterization of mulberry accessions in Turkey by AFLP markers. Journal of the American Society for Horticultural Science 133:593-597.

Kalinowski ST, Taper ML, Marshall TC (2007). Revising how the computer program CERVUS accommodates genotyping error increases success in paternity assignment. Molecular Ecology 16 (5):1099-1106.2

Minch E, Ruiz-Linares A, Goldstein DB, Feldman M, Cavalli-Sforza LL (1995). Microsat (Version 1.4d): a computer program for calculating various statistics on microsatellite allele data. Stanford University Medical Center, Stanford.

Orhan E, Ercisli S, Yildirim N, Agar G (2007). Genetic variations among mulberry genotypes (Morus alba) as revealed by random amplified polymorphic DNA (RAPD) markers. Plant Systematics and Evolution 265:251-258.

Orhan E (2009). Selection of mulberry types grown in Oltu and Olur district and determine genetic relationships among types by using RAPD methods. PhD, Atatürk University, Erzurum, Turkey.

Paetkau D, Calvert W, Stirling I, Strobeck C (1995). Microsatellite analysis of population structure in Canadian polar bears. Molecular Ecology 4:347-354.

Ramesh K, Aggarwal D, Udaykumar D, Hendre PS, Sarkar A, Singh LI (2004). Isolation and characterization of six novel microsatellite markers for mulberry (Morus indica). Molecular Ecology Notes 4:477-479.

Rohlf FJ (1988) NTSYS-PC Numerical Taxonomy and Multivariate Analysis System. Exeter Publishing, New York.

Sneath PH, Sokal RR (1973) Numerical Taxonomy. Freeman, San Francisco.

Thangavelu K, Mukherjee P, Tikader A, Ravindran S, Goel AK, Rao AA, ... Sekar S (1997). Catalogue on mulberry (Morus spp.) germplasm. Central Sericultural Germplasm Resource Centre, Hosur, Tamil Nadu, India.

Vijayan K, Chatterjee SN, Nair CV (2005). Molecular characterization of mulberry genetic resources indigenous to India. Genetic Resource and Crop Evolution 52:77-86.

Vijayan K, Chakraborti SP, Ercisli S, Ghosh PD (2008). NaCI induced morpho-biochemical and anatomical changes in mulberry (Morus spp.). Plant Growth Regulation 56(1):61-69.

Wagner HW, Sefc KM (1999). Identity 1.0. Centre for Applied Genetics. University of Agricultural Science, Vienna.

Wangari NP, Gacheri KM, Theophilus MM, Lucas N (2013). Use of SSR markers for genetic diversity studies in mulberry accessions grown in Kenya. International Journal for Biotechnology and Molecular Biology Research 4(3):3844.

Wani SA, Bhat MA, Malik GN, Zaki FA, Mir MR, Wani N, Bhat KM (2013). Genetic diversity and relationship assessment among mulberry (Morus spp) genotypes by simple sequence repeat (SSR) marker profile. African Journal of Biotechnology 12(21):3181-3187.

Yuan Q, Zhao L (2017). The Mulberry (Morus alba L.) fruit: A review of characteristic components and health benefits: Journal of Agricultural and Food Chemistry 65:10383-10394

Zhang H, Ma ZF, Luo X, Li X (2018). Effects of mulberry fruit (Morus alba L.) consumption on health outcomes: A mini-review. Antioxidants 7(5):69. 
Zhao W, Miao X, Jia S, Pan Y, Huang Y (2005). Isolation and characterization of microsatellite loci from the mulberry, Morus L. Plant Science 16:519-525.

Zhao W, Wang Y, Chen T, Ra G, Wang XM, Qi JL, ... Yang YH (2007). Genetic structure of mulberry from different ecotypes revealed by ISSRs in China: An implication for conservation of local mulberry varieties. Scientia Horticulturae 115:47-55.

OPEN ACCESS

(c) (1)
The journal offers free, immediate, and unrestricted access to peer-reviewed research and scholarly work. Users are allowed to read, download, copy, distribute, print, search, or link to the full texts of the articles, or use them for any other lawful purpose, without asking prior permission from the publisher or the author.

License - Articles published in Notulae Botanicae Horti Agrobotanici Cluj-Napoca are Open-Access, distributed under the terms and conditions of the Creative Commons Attribution (CC BY 4.0) License. (c) Articles by the authors; UASVM, Cluj-Napoca, Romania. The journal allows the author(s) to hold the copyright/to retain publishing rights without restriction. 